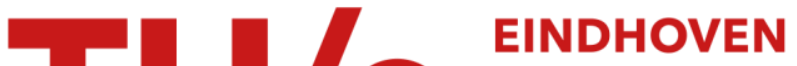 UNIVERSITY OF TECHNOLOGY
}

\section{Bidirectional K-band photonic/wireless link for 5G communications}

\section{Citation for published version (APA):}

Morales, A., Konstantinou, D., Rommel, S., Raddo, T. R., Johannsen, U., Okonkwo, C., \& Monroy, I. T. (2019). Bidirectional K-band photonic/wireless link for 5G communications. In IRMMW-THz 2019 - 44th International Conference on Infrared, Millimeter, and Terahertz Waves [08874031] Institute of Electrical and Electronics Engineers. https://doi.org/10.1109/IRMMW-THz.2019.8874031

DOI:

10.1109/IRMMW-THz.2019.8874031

Document status and date:

Published: 01/09/2019

\section{Document Version:}

Accepted manuscript including changes made at the peer-review stage

\section{Please check the document version of this publication:}

- A submitted manuscript is the version of the article upon submission and before peer-review. There can be important differences between the submitted version and the official published version of record. People interested in the research are advised to contact the author for the final version of the publication, or visit the $\mathrm{DOI}$ to the publisher's website.

- The final author version and the galley proof are versions of the publication after peer review.

- The final published version features the final layout of the paper including the volume, issue and page numbers.

Link to publication

\section{General rights}

Copyright and moral rights for the publications made accessible in the public portal are retained by the authors and/or other copyright owners and it is a condition of accessing publications that users recognise and abide by the legal requirements associated with these rights.

- Users may download and print one copy of any publication from the public portal for the purpose of private study or research.

- You may not further distribute the material or use it for any profit-making activity or commercial gain

- You may freely distribute the URL identifying the publication in the public portal.

If the publication is distributed under the terms of Article 25fa of the Dutch Copyright Act, indicated by the "Taverne" license above, please follow below link for the End User Agreement:

www.tue.nl/taverne

Take down policy

If you believe that this document breaches copyright please contact us at:

openaccess@tue.nl

providing details and we will investigate your claim. 


\title{
Bidirectional K-Band Photonic/Wireless Link for 5G Communications
}

\author{
A. Morales, D. Konstantinou, S. Rommel, T. R. Raddo, U. Johannsen, C. Okonkwo \\ and I. Tafur Monroy \\ Institute for Photonic Integration, Eindhoven University of Technology, 5600 MB Eindhoven, The Netherlands \\ Center for Wireless Technology, Eindhoven University of Technology, 5600 MB Eindhoven, The Netherlands \\ Email: a.morales.vicente@tue.nl
}

\begin{abstract}
A bidirectional analogue radio-over-fiber link relying on photonic heterodyning and time-division duplex is experimentally demonstrated, successfully transmitting 5G OFDM signals with data rates of $2.4 \mathrm{Gbit} / \mathrm{s}$ and $1.2 \mathrm{Gbit} / \mathrm{s}$ in down- and uplink directions over $4 \mathrm{~m}$ of wireless distance. An optical frequency comb laser is used together with a demultiplexing module based on injection locking to generate stable K-band $(18-27 \mathrm{GHz})$ signals, which eliminates the need for complex high-speed electronics for $\mathbf{m m}$-wave generation.
\end{abstract}

\section{INTRODUCTION}

$\mathrm{T}$ HE strong growth in mobile data traffic oblige to embrace new spectral assignments in the lower millimeter wave (mm-wave) range which, alongside the adapted flexible numerology for orthogonal frequency division multiplexing (OFDM) in $5 \mathrm{G}$ new radio (NR), will lead to data rates up to $10 \mathrm{~Gb} / \mathrm{s}$ [1,2]. Analogue radio-over-fiber (A-RoF) with mm-wave generation by optical heterodyning has been suggested as an efficient method for mobile fronthaul, providing seamless integration with existing optical distribution networks [3, 4]. However, the duplexing in the radio link, enabling bidirectional transport, is one of the key challenges to be addressed in mm-wave $5 \mathrm{G} \mathrm{NR}$, as it must afford sufficient flexibility to allow asymmetric resource allocation and to cope with varying channel conditions and signal quality between up- and downlink. Time division duplex (TDD), as defined for mm-wave 5G NR [2], is a simple duplex scheme which provides temporal separation of the uplink and downlink signal transmission as well as the capability of spectral reuse of the same frequency channels.

We experimentally demonstrate a bidirectional hybrid optical and wireless link based on A-RoF and TDD for 5G communications. This link can be directly integrated into optical distribution networks according to ultra-dense wavelength division multiplexing (UDWDM) standard. This is achieved by using photonic heterodyning based on an optical comb for both up- and downconversion to/from mm-wave.

\section{EXPERIMENTAL SETUP}

The experimental setup is depicted in Fig. 1. A frequency comb laser serves as light source for the entire system (optical spectrum in Fig. 1(a)). Four $12.5 \mathrm{GHz}$ spaced lines are demultiplexed by injection locking, matching the UDWDM grid. Two of them $\left(\lambda_{1}\right.$ and $\left.\lambda_{3}\right)$ are used in the downlink, while the other two $\left(\lambda_{2}\right.$ and $\left.\lambda_{4}\right)$ are employed in the uplink.

In the downlink, an OFDM signal, generated within and arbitrary waveform generator (AWG), is modulated onto $\lambda_{1}$ by using a Mach-Zehnder modulator (MZM). This signal is combined with $\lambda_{3}$, located $25 \mathrm{GHz}$ away, as well as $\lambda_{4}$ which will be used for the uplink with remote modulation. Two optical circulators connected to $15 \mathrm{~m}$ of standard single-mode

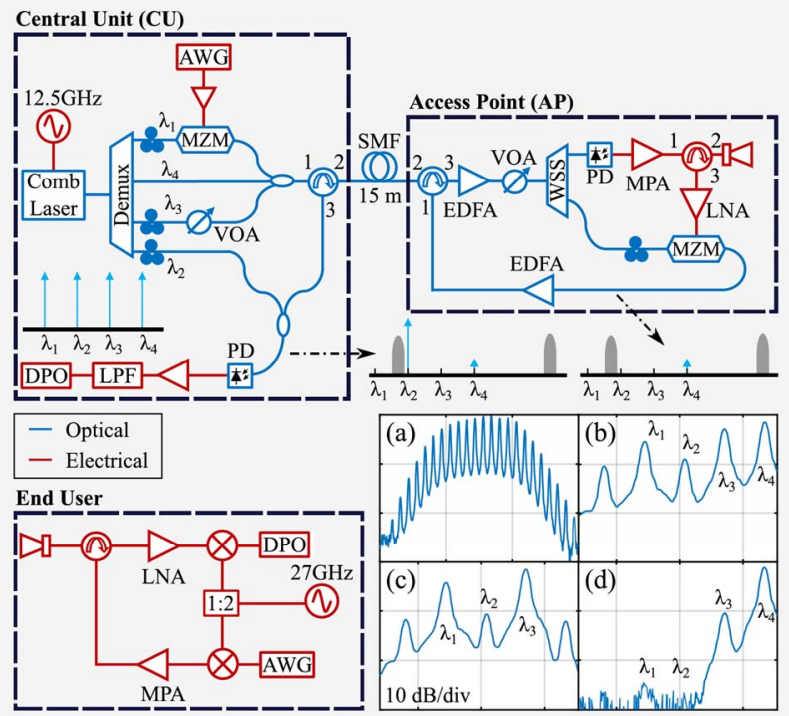

Fig. 1. Schematic of experimental setup and signal spectra: (a) comb spectrum, (b) optical spectrum before WSS, (c) optical spectrum incident on $\mathrm{PD}$ at remote station, (d) optical spectrum of tone for uplink transmission.

fiber (SMF) are used to allow bidirectional A-RoF transmission in a single fiber, as shown in Fig. 1.

At the access point, an erbium doped fiber amplifier (EDFA) and a variable optical attenuator (VOA) control the optical power available for wireless and uplink transmissions. The optical spectrum at this point is depicted in Fig. 1(b). In a further step, a wavelength selective switch (WSS) separates the signals for the downlink (modulated $\lambda_{1}$ and unmodulated $\lambda_{3}$, Fig, 1(c)) and the optical carrier for the uplink $\left(\lambda_{4}\right.$, Fig. 1(d)). The $25 \mathrm{GHz}$ signal is generated by photonic heterodyning on a high bandwidth photodiode (PD) [4]. This signal is first amplified by a $30 \mathrm{~dB}$ gain medium power amplifier (MPA), and then an electrical circulator isolates upand downlink directions. Finally, an $18 \mathrm{dBi}$ standard gain horn antenna radiates the downlink wave.

At the end user, after propagating over a wireless distance of $4 \mathrm{~m}$, the signal is received by an identical horn antenna attached to another electrical circulator. Later, it is boosted by a $40 \mathrm{~dB}$ gain low noise amplifier (LNA) and downconverted to an intermediate frequency (IF) by a mixer. A vector signal generator (VSG) at $27 \mathrm{GHz}$ serves as local oscillator (LO), resulting in an IF of $2 \mathrm{GHz}$. The IF wave is recorded by a digital phosphor oscilloscope (DPO) for off-line processing. In the uplink, a second OFDM signal is electrically upconverted to $\mathrm{K}$-band reusing the same $\mathrm{LO}$. The output wave at $27 \mathrm{GHz}$ is amplified by a $30 \mathrm{~dB}$ gain MPA and directed to the circulator for radiation via the antenna.

Again, at the access point, the received radio frequency (RF) signal from the end user is amplified by a $40 \mathrm{~dB}$ LNA 


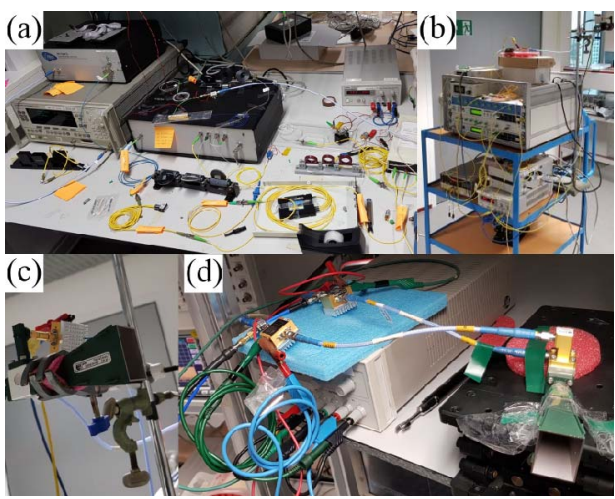

Fig. 2. Photographs of laboratory setup: (a) optical setup at central location, (b) setup at remote station, (c) antenna unit at remote station with circulator and LNA, (d) end user antenna unit with circulator, mixers and amplifiers.

before being used to modulate the uplink tone $\left(\lambda_{4}\right.$, Fig. $\left.1(\mathrm{~d})\right)$ in a MZM for optical transmission to the central unit, generating two side bands $27 \mathrm{GHz}$ away. At the central unit, the wave coming back through the uplink is isolated by a circulator and coupled with the fourth optical tone $\left(\lambda_{2}\right)$ extracted from the comb source. The relative frequency difference to the lower side band is $2 \mathrm{GHz}$, correspondingly heterodyne photonic downconversion produces an IF signal centered at $2 \mathrm{GHz}$. This technique considerably simplifies the receiver electronics. However, it should be mentioned that due to the path length difference between $\lambda_{4}$ and the upstream modulation, the phase noise of the mixing product may be high and may negatively affect the received signal. This issue implies a limitation in the maximum fiber length between the central unit and the access point, depending on laser and comb purity and stability and locking performance of the demultiplexer. Finally, the signal is amplified by a $19 \mathrm{~dB}$ gain amplifier and filtered by a $5.5 \mathrm{GHz}$ low pass filter to remove the unwanted frequency products. Again, a DPO is used to record the data for off-line processing. Figs. 2(a)-(d) show the described experimental setup in the laboratory.

\section{RESULTS}

The link is evaluated by measuring bit error rate (BER) after the wireless transmission of 4 band OFDM signals based on 5G NR numerology. These signals are generated by mapping QAM symbols originating from a random bit stream onto 4096 OFDM subcarriers spaced at $60 \mathrm{kHz}$. The signals for the two directions are chosen to have asymmetric properties in terms of data rate. In the downlink, where signal to noise ratio (SNR) is good, the transmitted OFDM subcarriers are modulated with 16-quadrature amplitude modulation (QAM) symbol, whereas in the uplink, where SNR is worse, quadrature phase-shift keying (QPSK) is used. The obtained data rates are $2.4 \mathrm{Gbit} / \mathrm{s}$ and $1.2 \mathrm{Gbit} / \mathrm{s}$ respectively, showing an asymmetric link determined by signal quality.

The BER results are shown in Fig. 2. In the downlink, BER is measured with respect to the optical power at the photodiode, while in the uplink is measured with respect to LO power supplied to the RF mixer. Downlink transmission is achieved with BER below the limit for a hard-decision forward error correction (FEC) with $7 \%$ overhead $(\mathrm{OH})$ and little variation is found with the optical power. The later can most likely be attributed to saturation of the receiver LNA.
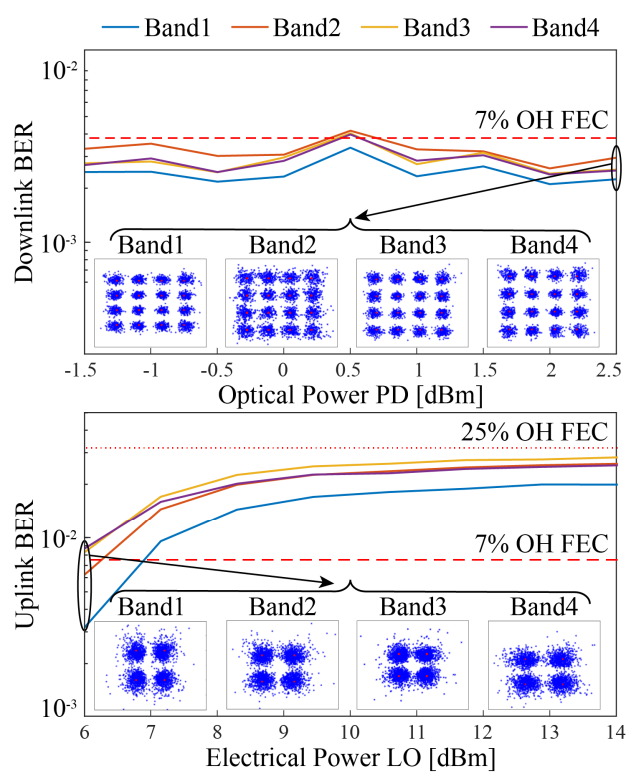

Fig. 3. BER performance of 4 band OFDM signals transmissions using 16QAM (downlink) and QPSK (uplink) symbols within $980 \mathrm{MHz}$ bandwidth.

In the uplink direction, the relation between electrical LO power and generated RF signal is less straight forward. Nevertheless, a similar behavior is seen, where for low powers BERs around the $7 \%$ OH FEC limit are obtained, while for higher powers again saturation of the receiver LNA causes the signal to degrade. In the saturated regime, BER is increased to the point that a FEC with $25 \% \mathrm{OH}$ would be required. Receiver LNA saturation appears to be the dominant limiting factor in the two cases; thus, a longer wireless transmission distance can be achieved.

\section{CONCLUSION}

A successful bidirectional multi-Gbit/s transmission of 5G NR OFDM signals through a K-band A-RoF link based on TDD was experimentally demonstrated. Data rates of $2.4 \mathrm{Gbit} / \mathrm{s}$ for down- and $1.2 \mathrm{Gbit} / \mathrm{s}$ for upstream were achieved over $4 \mathrm{~m}$ wireless distance within a bandwidth of $980 \mathrm{MHz}$ and with BERs below the limits for $7 \%$ and $25 \%$ OH FEC respectively. The presented work showcases comb-based A-RoF as a key enabler for bidirectional handling of $5 \mathrm{G} \mathrm{mm}$-wave signals, allowing fiber-wireless convergence and ultra-large capacities.

\section{ACKNOWLEDGEMENT}

Authors would like to thank Pilot Photonics Ltd. and Dublin City University (DCU) for lending the comb generator and demultiplexer to conduct the experiment. This work was partially funded by EU through the projects CELTA (no. 675683), 5G STEP FWD (no. 722429), blueSPACE (no. 762055) and 5G-PHOS (no. 761989).

\section{REFERENCES}

[1]. M. Xiao, et al., "Millimeter Wave Communications for Future Mobile Networks," IEEE. J. Sel. Areas Commun., vol. 35, no. 9, pp. 1909-1935, 2017. [2]. 3GPP TS 38.104, "NR: Base Station (BS) radio transmission and reception," Rel. 15, 3 GPP, Mar 2018.

[3]. S. Rodriguez, et al., "Real-time measurements of an optical reconfigurable radio access unit for 5G wireless access networks," Optical Fiber Communication Conference (OFC), pp. W1C.3, San Diego, USA, 2017. [4]. A. Morales, et al., "1 Gb/s chaotic encoded W-band wireless transmission for physical layer data confidentiality in radio-over-fiber systems," Opt. Express, vol.26, no. 17, pp. 22296-22306. 